\title{
Long-Term Transmission System Expansion Planning Using Valid Inequalities
}

\author{
Pedro Pablo Cárdenas Alzate \\ Department of Mathematics and GEDNOL, \\ Universidad Tecnológica de Pereira, Colombia.
}

\author{
Antonio Hernando Escobar Zuluaga \\ School of Electrical Technology, \\ Universidad Tecnológica de Pereira, Colombia.
}

\author{
Carlos Arturo Escudero Salcedo \\ Department of Mathematics and GIGP, \\ Universidad Tecnológica de Pereira, Colombia.
}

\begin{abstract}
In this paper, we present a methodology to solve the problem of optimization the expansion of long-term power transmission networks using a formulation that uses mathematical expressions that are alternatives to the Kirchhoff's second law and that are applied to the cycles critical of the system graph. The problem of planning transmission systems is part of the socalled NP-complete problems, which belong to a category of problems difficult to solve, for which no polynomial solution algorithms are known. The proposed methodology is applied to a test system from the specialized literature with very good results.
\end{abstract}

Keywords- Optimization, Critical cycles, Transmission planning, Kirchhoff's second law, NP-complete problems.

\section{INTRODUCTION}

The problem of planning the expansion of the electric power transmission net- work determines the new investments in transmission lines and substations, which are necessary to allow the adequate transfer of power between the different points of a system for future operation (Correa et al., 2014).

The options associated with this problem are characterized by their high investment costs, as well as the large construction periods and their long recovery times of the investment made. For this type of problems, the planning studies take as a reference the current network and consider the increase in demand in the system nodes, the new generation alternatives and the improvement in power (existing generation), in a time horizon which is usually greater than 10 years. Static planning determines the minimum cost solution from the approach of an optimization problem which considers that the existing network is part of the future solution, which means that it is not considered the possibility of withdrawing, transferring or leaving disconnected fix elements that are operating in the current network (Monticelli et al., 1982).

This paper presents two novel relaxed models (Escobar, 2018; Dominguez, 2018) and proposes a novel cycle-based model formulation to solve the transmission planning problem using the so-called: improved disjunctive transport model and a cycle-based formulation. The transport model can be presented using an alternative form: the disjunctive transport model. This model has more variables and limitations than the traditional transport model, but it can be useful in other contexts.

\section{MATHEMATICAL MODEL}

The great disadvantage of the disjunctive model is Kirchhoff's second law, which makes the problem more difficult. This is the main characteristic of the normal behavior of the transmission planning problem used in this work to create different methods to improve the computational effort and build the path to find better solutions in the future. In this case, the main objective is to find the best representation of Kirchhoff's second law to replace it and result in a simpler model that can be solved in less time (Escobar, 2010; Dominguez, 2014).

\subsection{Disjunctive transport model}

One of the most widely used models for solving the transmission planning problem is the transport model, which represents the simplest form of the planning problem and is easy to solve, in which Kirchhoff's second law is not used, the main reason why even large problems had a solution in a relatively short time as the total time needed to solve it. In this disjunctive version presented in (Escobar, 2018; Rider, 2008), we use binary variables for the investment options and disjunctive constraints. The formulation of this model is:

$$
\min v=\sum_{(i, j) \in \Omega} C_{i j} \sum_{k \in K} y_{i j, k}
$$

s.t. $\sum_{(p, i) \in \Omega_{1}}\left(f_{p i}^{0}+\sum_{k \in K} f_{p i, k}\right)-\sum_{(i, j) \in \Omega}\left(f_{i j}^{0}+\sum_{k \in K} f_{i j, k}\right)+$ $g_{i}=d_{i}$ 
International Journal of Engineering Research and Technology. ISSN 0974-3154, Volume 13, Number 10 (2020), pp. 2768-2777

(C) International Research Publication House. https://dx.doi.org/10.37624/IJERT/13.10.2020.2768-2777

$$
\begin{aligned}
& \left|f_{i j}^{0}\right| \leq n_{i j}^{0} \bar{f}_{i j}, \quad \forall(i, j) \in \Omega \\
& \left|f_{i j, k}\right| \leq y_{i j, k} \bar{f}_{i j}, \quad \forall(i, j) \in \Omega, k \in K \\
& 0 \leq g_{i} \leq \bar{g}_{i}, \quad \forall i \in B \\
& \sum_{k \in \Omega_{1}} y_{i j, k} \leq \bar{n}_{i j}, \quad \forall(i, j) \in \Omega \\
& y_{i j, k-1} \geq y_{i j, k}, \quad \forall(i, j) \in \Omega, k \in K, k>1 \\
& f_{i j, k}, f_{i j}^{0}, \theta_{i}, g_{i} \text { unrestricted }
\end{aligned}
$$

In the previous model, $\mathrm{C}_{\mathrm{ij}}$ is the cost of adding a circuit in the branch $i j$ between buses $i$ and $j . \Omega_{1}$ is the set of transmission corridors existing. $\mathrm{y}_{\mathrm{ij}, \mathrm{k}}$ is the binary variable associated with the investment option $k$ of the $i j$ corridor. $\mathrm{f}_{\mathrm{ij}}^{0}$ is the base network; $\overline{\mathrm{f}}_{\mathrm{ij}}$ is the maximum flow allowed for a circuit on the $i j$ path in an existing corridor. $\bar{g}$ is the maximum nodal generation vector. $\mathrm{n}_{\mathrm{ij}}$ is the number of reinforcements added in the $i j$ corridor of the base network, while $\overline{\mathrm{n}}_{\mathrm{ij}}$ is the maximum number of circuits that can be added in the $i j$ corridor. $M$ is a parameter defined a priori of large size, which makes the restrictions irrelevant when the variable $\mathrm{y}_{\mathrm{ij}, \mathrm{k}}=1$.

\subsection{Improved disjunctive transport model}

Taking as reference the disjunctive transport model, this model presented in (Escobar, 2018), adds a new set of restrictions that will include the behavior of Kirchhoff's second law only for parallel circuits, without using this law. This is achieved by forcing the flow of energy to be distributed equally in each parallel circuit. It may be obvious that circuits of equal reactance, connected in parallel, transport equal flow, however, in the traditional transport model the solutions present different flows in this case. This is because the traditional transport model does not include Kirchhoff's second law (Kocuk, 2016). The improved disjunctive transport model used in this work is a relaxed version of the linear disjunctive model and can find intermediate solutions between the traditional transport model and the DC linear disjunctive model.

$$
\min v=\sum_{(i, j) \in \Omega_{1}} C_{i j} \sum_{k \in \Omega_{2}} y_{i j, k}
$$

s.t. $\sum_{(p, i) \in \Omega_{1}}\left(f_{p i}^{0}+\sum_{k \in \Omega_{2}} f_{p i, k}\right)-\sum_{(i, j) \in \Omega_{1}}\left(f_{i j}^{0}+\right.$

$\left.\sum_{k \in \Omega_{2}} f_{i j, k}\right)+g_{i}=d_{i}$

$$
\left|f_{i j}^{0}\right| \leq n_{i j}^{0} \bar{f}_{i j}, \quad \forall(i, j) \in \Omega_{1}
$$

$$
\begin{aligned}
& \left|f_{i j, k}\right| \leq y_{i j, k} \bar{f}_{i j}, \quad \forall(i, j) \in \Omega_{1}, k \in \Omega_{2} \\
& 0 \leq g_{i} \leq \bar{g}_{i}, \forall i \in B \\
& \sum_{k \in \Omega_{2}} y_{i j, k} \leq \bar{n}_{i j}, \quad \forall(i, j) \in \Omega_{1} \\
& y_{i j, k-1} \geq y_{i j, k}, \quad \forall(i, j) \in \Omega_{1}, k \in \Omega_{2}, k>1 \\
& \left|f_{i j, k}-f_{i j, k-1}\right| \leq M\left(1-y_{i j, k}\right), \forall(i, j) \in \Omega_{1}, k \in \Omega_{2}, k>1 \\
& \left|f_{i j}^{0}\right|_{n_{i j}^{0}-f_{i j, 1} \mid \leq M\left(1-y_{i j, 1}\right), \forall(i, j) \in \Omega_{1}, k \in \Omega_{2}, n_{i j}^{0}>0} \\
& f_{i j, k}, f_{i j}^{0}, \theta_{i}, g_{i} \text { unrestricted }
\end{aligned}
$$

In the previous model (9) it represents the objective function and characterizes traditional planning as a minimum cost problem. The restriction (10) represents the Kirchhoff's first law. The restriction (11) allows to establish the limits of capacity in the existing circuits and the (12) in the non-existing circuits. Through (13) the limits of generation are established and (14) it establishes the limit of investment. (15) it establishes an order of priority among the investment options and eliminates the existing symmetry between these options in the traditional disjunctive transport model. (16) and (17) ensure that active power flows are equal in circuits connected in parallel in the same corridor [3].

In this model, the same nomenclature presented above is used.

\subsection{Mathematical models that consider multiple stages}

In the static planning of the transmission, a single investment is made, defining where and how many (new) elements must be installed in the system for it to work correctly in the study time horizon ( $t$ years). However, during this period of time, changes in generation and demand occur that can be assumed by new investments made gradually over the time horizon, thus allowing the system to be coupled in an optimized manner. This way of assuming the problem is known as multi-stage planning, since it defines when the new elements must be installed in the system.

In this type of planning, decisions on investments in the transmission network are separated into periods of time below the planning horizon. For each of these periods, it is important to foresee values of installed generation capacity and active power demand, making it possible to determine not only the quantity and location of new equipment, but also which of the stages must be installed. Therefore, this last aspect is what distinguishes multi-stage planning from static planning of transmission networks. 
The objective function of the multi-stage planning problem is to minimize the value present of the total cost of the expansion of the transmission network. When certain investments are deferred for later stages, the present value of those investments is linked by an $I(t)$ discount rate.

$$
\begin{gathered}
c(x)=(1-I)^{t_{i}-t_{0}} c_{1}(x)+(1-I)^{t_{2}-t_{0}} c_{2}(x)+\cdots \\
+(1-I)^{t_{T}-t_{0}} c_{T}(x)
\end{gathered}
$$

It can be seen that in multi-stage planning, it is a matter of approximating the modeled problem to the real-life problem, where first the investment is made and years later the construction stage is completed and the element enters into operation for each stage analyzed. Another important element of the model is that it is considered that in each period of operation the demand is always constant, that is, the demand projection for an initial period is constant and different from the demand projection of the subsequent period and so on. Now, with respect to the generation projection, this may be the same or different between the periods of operation, according to the planning of the expansion in generation, which is considered an input to the planning.

Finally, for the calculation of the present value of the investment and the cost of the operation also called cost of the losses, an annual discount rate $\alpha$ is considered which represents the expected economic return for the money over time. However, to compare the cost of the multi-stage model with the static one, the present value is used, being evident that with the inclusion of the annual discount rate, the multi-stage planning could be more economic. This is possible due to the same assumption made in the static analysis, where it is established that the money to carry out the expansion of the system is available in the initial year. Thus, the difference in the cost of the multi-stage analysis has its origin in that the investments are divided in time and it is possible to know the best moment in which they are required by the system, so it is possible to somehow delay the putting in place of new elements that are not urgent (in the system) and which can be put in later stages (Romero et al., 2005).

The mathematical model for multi-stage planning is defined below. It is the result of a detailed study (aspects) of the models studied, which allows it to be presented in the linearized version. As for the parameters and variables used, they present the sub-index $t$ indicating the time in the investment or operation period for which they work. It is clear that the $t$ index increases the number of variables and parameters according to the number of stages considered.

\subsubsection{Improved multi-stage transport model}

This model in multi-stage version has the form:

$$
\begin{aligned}
& \min v=\alpha^{0} \sum_{(i, j) \in \Omega} C_{i j} \sum_{k=1}^{K} y_{i j, k}^{0}+\sum_{t=2}^{T} \alpha^{t} \sum_{(i, j) \in \Omega} C_{i j}\left(\sum_{k=1}^{K} y_{i j, k}^{t}-\sum_{k=1}^{K} y_{i j, k}^{t-1}\right) \\
& \text { s.t. } \sum_{(p, i) \epsilon \Omega}\left(f_{p i}^{0, t}+\sum_{k=1}^{K} f_{p i, k}^{t}\right)-\sum_{(i, j) \epsilon \Omega}\left(f_{i j}^{0, t}+\sum_{k=1}^{K} f_{i j, k}^{t}\right)+g_{i}^{t}=d_{i}^{t}, \quad \forall i \epsilon B, t \in T \\
& \left|f_{i j}^{0, t}\right| \leq n_{i j}^{0} \overline{f_{l j}}, \quad \forall(i, j) \in \Omega, t \in T \\
& \left|f_{i j, k}^{t}\right| \leq y_{i j, k}^{t-1} \overline{f_{l j}}, \quad \forall(i, j) \in \Omega, t \in T, k=1,2, \ldots, K \\
& \sum_{k=1}^{K} \quad y_{i j, k}^{t-1} \leq \bar{n}_{i j}, \quad \forall(i, j) \in \Omega, t \in T \\
& y_{i j, k}^{t-1} \leq y_{i j, k-1}^{t-1}, \quad k \geq 2, \forall(i, j) \in \Omega, t \in T \\
& \left|f_{i j, k}^{t}-f_{i j, k-1}^{t}\right| \leq M\left(1-y_{i j, k}^{t-1}\right), \quad \forall(i, j) \in \Omega, k=1,2, \ldots, K, k>1, t \in T \\
& \left|f_{i j}^{0} / n_{i j}^{0}-f_{i j, 1}\right| \leq M\left(1-y_{i j, k}^{t-1}\right), \quad \forall(i, j) \in \Omega, t \in T \\
& 0 \leq g_{i}^{t} \leq \bar{g}_{i}^{t}, \quad \forall i \in B, t \in T \\
& f_{i j,}^{0}, f_{i j, k}^{t}, g_{i}^{t} \text { unrestricted } \quad \forall \\
& y_{i j, k}^{t} \text { binary } \quad \forall
\end{aligned}
$$




\subsubsection{Multi-stage linear disjunctive model}

According to the reduced linear disjunctive model, the form taken by the planning problem of multi-stage transmission network expansion is as follows:

$$
\begin{aligned}
& \min v=\alpha^{0} \sum_{(i, j) \epsilon \Omega} C_{i j} \sum_{k=1}^{K} y_{i j, k}^{0}+\sum_{t=1}^{T} \alpha^{t} \sum_{(i, j) \epsilon \Omega} C_{i j}\left(\sum_{k=1}^{K} y_{i j, k}^{t}-\sum_{k=1}^{K} y_{i j, k}^{t-1}\right) \\
& \text { s.t. } \sum_{(p, i) \epsilon \Omega}\left(f_{p i}^{0, t}+\sum_{k=1}^{K} f_{p i, k}^{t}\right)-\sum_{(i, j) \epsilon \Omega}\left(f_{i j}^{0, t}+\sum_{k=1}^{K} f_{i j, k}^{t}\right)+g_{i}^{t}=d_{i}^{t}, \forall i \in B, t \in T \\
& \left|f_{i j}^{0}\right| \leq n_{i j}^{0} \overline{f_{l j}}, \quad \forall(i, j) \in \Omega, t \in T \\
& \left|f_{i j, k}^{t}\right| \leq y_{i j, k}^{t-1} \overline{f_{l j}}, \forall(i, j) \in \Omega, t \in T, k=1,2, \ldots, K \\
& f_{i j}^{0, t} x_{i j}-\left(\theta_{i}^{t}-\theta_{j}^{t}\right) n_{i j}^{0}=0, \forall(i, j) \in \Omega, t \in T \\
& -M\left(1-y_{i j, k}^{t-1}\right) \leq x_{i j} f_{i j, k}^{t}-\left(\theta_{i}^{t}-\theta_{j}^{t}\right) \leq M\left(1-y_{i j, k}^{t-1}\right), \quad \forall(i, j) \in \Omega, t \in T, k=1,2, \ldots, K \\
& 0 \leq g_{i}^{t} \leq \bar{g}_{i}^{t}, \forall i \in B, t \in T \\
& \sum_{k=1}^{K} y_{i j, k}^{t-1} \leq \bar{n}_{i j}, \forall(i, j) \in \Omega, t \in T \\
& y_{i j, k}^{t-1} \leq y_{i j, k-1}^{t-1}, \quad k \geq 2, \forall(i, j) \in \Omega, t \in T \\
& \theta_{i}^{j}=0, \forall i \in B, t \in T \\
& f_{i j}^{0}, f_{i j, k}^{t}, g_{i}^{t}, \theta_{i}^{t} \text { unrestricted } \\
& y_{i j, k}^{t} \text { binary }
\end{aligned}
$$

This model is constructed in such a way that additions from a previous stage are accumulated in the decision variables of the following stages. The calculation of the investment cost or objective function is made in the expression (19). To differentiate in which stage each of the investments of new elements is made, a comparison of the binary variables of the same element in the following stages is made, this is achieved through the difference of the binary variables. The set of restrictions (20) represents the Kirchhoff's first law, in which the balance of active power flows in each of the system's nodes is required in each of the stages of the planning horizon. The restriction sets (21) and (22) represent the active power flow limits of the base network and the new elements to be added in the transmission network during each of the stages. Constraints (23) and (24) require compliance with the Kirchhoff's second law for all transmission grid corridors during all stages of the planning horizon. A distinction is made between base network elements and candidate elements, in order to apply the characteristic linearization of the model. The constraints of (25) and (26) represent the generation and investment limits. The restrictions (27) give priority for investment to the binary variables of lower $k$ index. This is done to reduce the search space and does not affect the value of the solution. Finally, conditions (28) - (30) define the nature of each of the decision variables.

\section{FORMULATION OF THE CYCLES}

We use below the basic terminology of graph theory, which will guide us to the definition of the cycle. An unguided graph $G$ is a pair $(V, E)$, where $V$ is a finite set and $E$ is a family of (unordered) pairs of elements of $V$. The elements of $V$ are called nodes or vertices and the elements of $E$ are called paths or corridors of $G$. Given a corridor between two vertices $i, j \in V$, with $i=j$, we denote this corridor by $(i, j)$. Therefore, for a corridor $e=(i, j) \in E, \mathrm{i}$ and $j$ are called their final points or vertices. In the same way we say that the corridor $e$ is incident to the vertices $i$ and $j$. Similarly, we say that the vertex $i$ is adjacent to the vertex $j$. It is important to note that as we assume an untargeted graph, the adjacency relation is symmetric. The degree of a vertex in a non-directed graph is the number of sides incident to it, which we will denote as $\operatorname{deg}\left(i_{q}\right)$.

A path $p$ of length $k$, which joins a vertex $i$ to a vertex $j$, in a graph $G(V, E)$, is a sequence $\left\langle r_{0}, r_{1}, \ldots, r_{k}\right\rangle$ of vertices such that: $i=r_{0}, j=r_{k}$,

with $\left(r_{m-1}, r_{m}\right) \in E$ for $m=1,2, \ldots, k$. A path is simple if all its vertices are different. In a non-directed graph, a path $\left\langle r_{0}, r_{1}, \ldots, r_{k}\right\rangle$ forms a cycle if $r_{0}=r_{k}$ and $r_{1}, r_{2}, \ldots, r_{k}$ are different.

A graph $G^{\prime}=\left(V^{\prime}, E^{\prime}\right)$ is a subgraph of $G=(V, E)$ if $V^{\prime} \subseteq$ $V$ and $E^{\prime} \subseteq E$. Given a set $V^{\prime} \subseteq V$, the subgraph of $G$ induced by $V^{\prime}$ is the graph $G^{\prime}=\left(V^{\prime}, E^{\prime}\right)$ where $E^{\prime}=\left\{\left(i_{1}, i_{2}\right) \in\right.$ $\left.E: i_{1}, i_{2} \in V^{\prime}\right\}$.

\subsection{Cycle basis}

Let $G=(V, E)$ be an unmanaged graph with $m$ sides and $n$ vertices. A cycle of $G$ is a subgraph of $G$ where each vertex has an even side. Now, associated with each cycle $C$ there is a value $w_{i j}$ on $E$, where for any $e \in E$, 
International Journal of Engineering Research and Technology. ISSN 0974-3154, Volume 13, Number 10 (2020), pp. 2768-2777

(C) International Research Publication House. https://dx.doi.org/10.37624/IJERT/13.10.2020.2768-2777

$w_{i j}=\left\{\begin{array}{l}1, \\ -1, \\ 0,\end{array}\right.$ if $i j$ has the orientation of $C$

if ij has opposite orientation to that of $C$

another case
The vector space generated by the incident vectors of cycles is called the space of cycles of $G$, which has the dimension

$$
m-n+\alpha(G),
$$

where $m$ is the number of sides of $G, \mathrm{n}$ is the number of nodes or vertices and $\alpha(G)$ is the number of connected components of $G$. A maximal set of linearly independent cycles is called a cycle basis.

\section{PROPOSED METHODOLOGY}

The idea is to replace the Kirchhoff's second law by cycles, that is,

$$
\sum_{(i, j) \in C}\left(\theta_{i}-\theta_{j}\right)=\sum_{(i, j) \in C} w_{i j} f_{i j} x_{i j}=0
$$

where $C$ is any directed cycle and $x_{i j}$ is the reactance in the path $(i, j)$. Therefore, the mathematical model for the planning problem of the long-term expansion of transmission systems involving Kirchhoff's second law can be modified using the model given by equations (9)-(18) and enclosing the cycles minimums given by (31).

\subsection{General form of the minimum cycles}

In an expansion planning problem, given the initial network of the system and future generation data, future demand and characteristics of the options for investment in lines and transformers, the problem is solved using the model of disjunctive transport (which does not include Kirchhoff's second law), and is verified in the response if circuits appear in their maximum capacity or circuits added in new corridors. The cycle containing these circuits is determined continuously and is a cycle with minimum sum of weights. These cycles, called critical cycles, are added to the transport model and the process is repeated until new circuits do not appear at their upper limit or new circuits are not added in new corridors.

When the critical cycles are formed exclusively by existing corridors, their general form is:

$$
\sum_{(i, j) \in C} w_{i j}\left(\frac{f_{i j}^{0}}{n_{i j}^{0}}\right) x_{i j}=0 .
$$

As an example of application, suppose a critical cycle takes the following form:

$$
\begin{gathered}
\left(\frac{f_{12}^{0}}{n_{12}^{0}}\right) x_{12}+\left(\frac{f_{25}^{0}}{n_{25}^{0}}\right) x_{25}+\left(\frac{f_{58}^{0}}{n_{58}^{0}}\right) x_{58}-\left(\frac{f_{78}^{0}}{n_{78}^{0}}\right) x_{78} \\
-\left(\frac{f_{17}^{0}}{n_{17}^{0}}\right) x_{17}=0,
\end{gathered}
$$

Which corresponds to the succession of vertices $\langle 1,2,5,8,7,1\rangle$. The positive terms correspond to links that have the same orientation of the cycle and the negative terms to links that have the opposite orientation of the cycle.
Now, if one of the cycles involves new proposals, then we must add to equation (32) the part corresponding to the disjunctive condition, that is,

$$
\begin{aligned}
& \sum_{(i, j) \in C_{1}} w_{i j}\left(\frac{f_{i j}^{0}}{n_{i j}^{0}}\right) x_{i j}+\sum_{(i, j) \in C_{2}} w_{i j} f_{i j, 1} x_{i j} \leq M(z- \\
& \left.\sum_{(i, j) \in C_{2}} y_{i j, 1}\right), \forall(i, j) \in C,
\end{aligned}
$$

where $C_{1}$ represents the subset of links of the critical cycle $C$, associated to circuits in existing corridors, $C_{2}$ represents the subset of links of the critical cycle $C$, associated with circuits in new corridors, $\mathrm{z}$ is the number of links contained in $C_{2}$ to which are associated variables decision binaries $y_{i j, 1}$. For example, if one of the critical cycles involving new corridors (see equation (33)) corresponds to the succession of vertices $\langle 5,6,46,19,18,13,8,5\rangle$, this cycle takes the following form

$$
\begin{aligned}
&\left\{\left(f_{5-6,1}\right) x_{5-6}+\right.\left(f_{6-46,1}\right) x_{6-46}-\left(\frac{f_{19-46}^{0}}{n_{19-46}^{0}}\right) x_{19-46} \\
&-\left(\frac{f_{18-19}^{0}}{n_{18-19}^{0}}\right) x_{18-19}-\left(\frac{f_{13-18}^{0}}{n_{13-18}^{0}}\right) x_{13-18}- \\
&\left.\left(\frac{f_{8-13}^{0}}{n_{8-13}^{0}}\right) x_{8-13}-\left(\frac{f_{5-8}^{0}}{n_{5-8}^{0}}\right) x_{5-8}\right\} \leq M\left(2-y_{5-6,1}-y_{6-46,1}\right)
\end{aligned}
$$

\section{CASE STUDY AND NUMERICAL RESULTS}

When we use the Improved Disjunctive Transport Model and the base cycles, the problem is solved with the transport model, with the objective of finding all the corridors that have circuits with flow at maximum capacity (Zeinaddini et al., 2011). Now, based on this, the corridors that present such a characteristic will represent the starting point in the analysis, that is, first it is observed that corridors have the maximum active power flow in the results found with the transport model. Later, these corridors are identified in the power system to define which ones can close a minimum cycle with it, and finally, with this cycle new restrictions are created that are added to the improved transport model.

\subsection{Colombian system}

The Colombian test system (see Figure 1.) is made up of 93 nodes and 155 transmission circuits (Escobar, 2002; Romero et al., 2005). By applying the proposed methodology to the Colombian system, the critical cycles presented below are obtained (see Table 1). Cycles 1, 2 and 49 presented in the previous table involve new corridors, and correspond to a disjunctive restriction. With the proposed methodology applied to the Colombian electrical system (using the disjunctive 
transport model), 50 critical cycles were obtained, which allow finding the optimum solution known for this system of US $\$ 562.417$. The execution time was $62.79 \mathrm{sec}$ with 96484.45 ticks (53.1\% of the disjunctive linear model). As in the previous system, the methodology proposed in this work allows to obtain better results in computation times, that is, with the traditional disjunctive model the same optimal solution is obtained but with an execution time of $99.25 \mathrm{sec}$ with 147153.02 ticks, which evidences the effectiveness of the proposal with cycles.
As a partial conclusion, the DC model is considered the ideal model to solve the transmission planning problem, which can be replaced by the improved disjunctive transport model, in addition to the set of critical system cycles. In medium sized systems and in highly complex systems, this proves to be a promising technique to reduce time and computational effort.

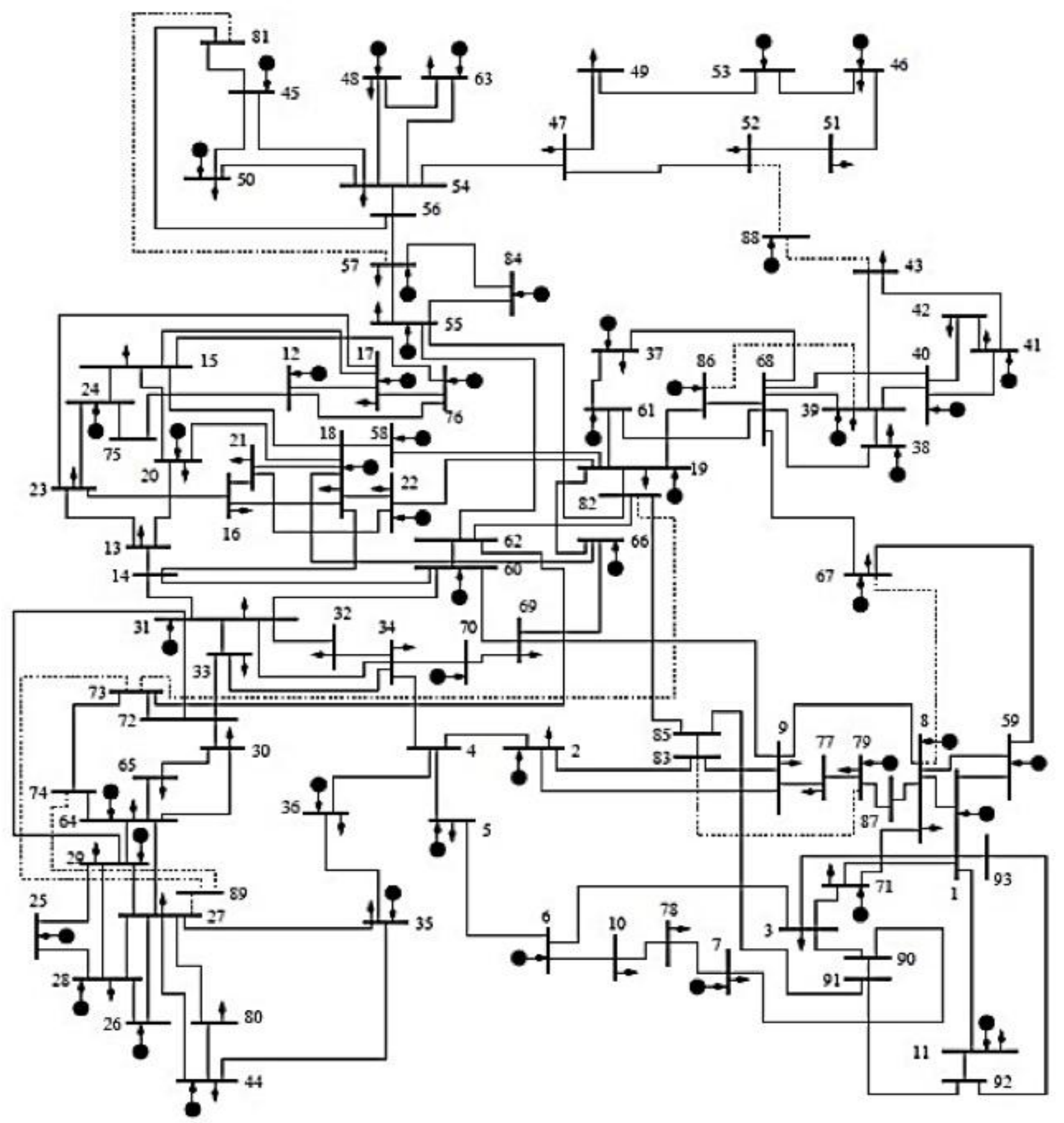

Figure 1. The Colombian test system. 
International Journal of Engineering Research and Technology. ISSN 0974-3154, Volume 13, Number 10 (2020), pp. 2768-2777

(C) International Research Publication House. https://dx.doi.org/10.37624/IJERT/13.10.2020.2768-2777

Table 1. Critical cycles for the Colombian system.

\begin{tabular}{|c|c|}
\hline Ciclo $1^{*}$ & $\langle 52,88,43,39,68,86,19,82,55,57,56,54,47,52\rangle$ \\
\hline Ciclo $2^{*}$ & $\langle 57,81,56,57\rangle$ \\
\hline Ciclo 3 & $\langle 25,28,29,25\rangle$ \\
\hline Ciclo 4 & $\langle 14,31,60,14\rangle$ \\
\hline Ciclo 5 & $\langle 14,18,20,13,14\rangle$ \\
\hline Ciclo 6 & $\langle 2,83,9,69,70,34,4,2\rangle$ \\
\hline Ciclo 7 & $\langle 15,18,20,15\rangle$ \\
\hline Ciclo 8 & $\langle 19,61,68,86,19\rangle$ \\
\hline Ciclo 9 & $\langle 61,68,37,61\rangle$ \\
\hline Ciclo 10 & $\langle 24,75,12,76,17,23,24\rangle$ \\
\hline Ciclo 11 & $\langle 27,35,44,27\rangle$ \\
\hline Ciclo 12 & $\langle 45,50,54,45\rangle$ \\
\hline Ciclo 13 & $\langle 59,67,68,61,19,66,69,9,8,59\rangle$ \\
\hline Ciclo 14 & $\langle 8,59,1,8\rangle$ \\
\hline Ciclo 15 & $\langle 1,3,71,1\rangle$ \\
\hline Ciclo 16 & $\langle 55,62,82,55\rangle$ \\
\hline Ciclo 17 & $\langle 66,69,60,14,18,66\rangle$ \\
\hline Ciclo 18 & $\langle 9,69,70,34,4,2,9\rangle$ \\
\hline Ciclo 19 & $\langle 31,32,34,31\rangle$ \\
\hline Ciclo 20 & $\langle 16,18,21,16\rangle$ \\
\hline Ciclo 21 & $\langle 31,34,33,72,31\rangle$ \\
\hline Ciclo 22 & $\langle 31,33,72,31\rangle$ \\
\hline Ciclo 23 & $\langle 31,60,69,70,34,32,31\rangle$ \\
\hline Ciclo 24 & $\langle 18,20,13,23,16,18\rangle$ \\
\hline Ciclo 25 & $\langle 18,66,19,58,18\rangle$ \\
\hline
\end{tabular}

\begin{tabular}{|c|c|}
\hline Ciclo 26 & $\langle 19,22,21,18,58,19\rangle$ \\
\hline Ciclo 27 & $\langle 17,23,24,15,17\rangle$ \\
\hline Ciclo 28 & $\langle 27,28,29,27\rangle$ \\
\hline Ciclo 29 & $\langle 1,8,71,3,1\rangle$ \\
\hline Ciclo 30 & $\langle 19,58,18,22,19\rangle$ \\
\hline Ciclo 31 & $\langle 27,64,29,27\rangle$ \\
\hline Ciclo 32 & $\langle 27,44,80,27\rangle$ \\
\hline Ciclo 33 & $\langle 26,27,28,26\rangle$ \\
\hline Ciclo 34 & $\langle 27,29,25,28,27\rangle$ \\
\hline Ciclo 35 & $\langle 64,65,30,72,73,74,64\rangle$ \\
\hline Ciclo 36 & $\langle 4,34,33,72,30,64,27,35,36,4\rangle$ \\
\hline Ciclo 37 & $\langle 8,9,77,79,87,8\rangle$ \\
\hline Ciclo 38 & $\langle 23,24,15,18,14,13,23\rangle$ \\
\hline Ciclo 39 & $\langle 6,10,78,7,90,3,6\rangle$ \\
\hline Ciclo 40 & $\langle 45,81,56,54,45\rangle$ \\
\hline Cycle 41 & $\langle 64,74,73,72,30,64\rangle$ \\
\hline Ciclo 42 & $\langle 72,73,62,60,31,72\rangle$ \\
\hline Ciclo 43 & $\langle 19,82,62,60,69,66,19\rangle$ \\
\hline Ciclo 44 & $\langle 82,85,83,9,69,60,62,82\rangle$ \\
\hline Ciclo 45 & $\langle 1,93,92,11,1\rangle$ \\
\hline Ciclo 46 & $\langle 9,83,85,91,90,3,71,8,9\rangle$ \\
\hline Ciclo 47 & $\langle 29,31,72,30,64,29\rangle$ \\
\hline Ciclo 48 & $\langle 85,91,92,93,1,8,9,83,85\rangle$ \\
\hline Ciclo $49^{*}$ & $\langle 27,89,74,64,27\rangle$ \\
\hline Ciclo 50 & $\langle 4,5,6,3,71,8,9,2,4\rangle$ \\
\hline
\end{tabular}

\subsection{Multi-stage planning using critical cycles}

As mentioned above, the main difference between static planning and multi-stage planning is that the latter considers the existence of planning stages (time). The process of identifying separable variables and reducing the space solution for the multi-stage planning problem is executed based on the proposed methodology (critical cycles).

\subsubsection{Colombian multi-stage test system}

The Colombian system was first presented in (Escobar, 2002) and has been used as evidence in a large number of papers. It is a system of great size and average complexity, which is constituted by 93 nodes and 155 transmission lines candidates. The optimal solution in the static case reported in the specialized literature has a solution of $U S \$ 560 \times 10^{6}$ with a cut-off load of less than $1 \mathrm{MW}$ and a solution of $U S \$ 562 \times 10^{6}$ with a cut-off load of $0 \mathrm{MW}$.

For the case of multi-stage planning, the planning horizon is divided into three periods representing a discrete growth until the final horizon of the static system 2012. Figure 2 shows a representation over time of the costs involved in expanding system capacity. The year $t_{0}=2002$ serves as the basis for the 
International Journal of Engineering Research and Technology. ISSN 0974-3154, Volume 13, Number 10 (2020), pp. 2768-2777

(C) International Research Publication House. https://dx.doi.org/10.37624/IJERT/13.10.2020.2768-2777

calculation of present values of investment costs and in this case, corresponds to the lower limit of the planning horizontal. The year $t_{3}$ is the upper limit of this horizon (Escobar, 2002). Finally, it is considered that the equipment linked to the investments of stage $k$ should be available to operate from the moment $t_{k}$.

The best reported solution for this test system (Rahmani et al., 2013) has a cost of $U S \$ 500.1719851$. Data for this system can be found at (Duque, 2014) and (Escobar, 2002).

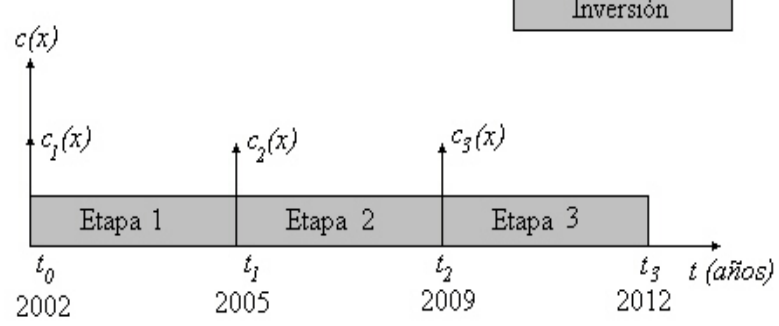

Figure 2. Colombian system with 3 planning stages.

However, for this system, the critical cycles presented below are obtained (see Table 2).

Table 2. Critical cycles for the Colombian multi-stage test system.

\begin{tabular}{|c|c|}
\hline Ciclo $1^{(1,2,3)}$ & $\langle 25,28,29,25\rangle$ \\
\hline Ciclo $2^{(1,2,3)}$ & $\langle 14,18,20,13,14\rangle$ \\
\hline Ciclo $3^{(1,2,3)}$ & $\langle 2,83,9,69,70,34,4,2\rangle$ \\
\hline Ciclo $4^{(1,2,3)}$ & $\langle 15,18,20,15\rangle$ \\
\hline Ciclo $5^{(1,2,3)}$ & $\langle 17,76,15,17\rangle$ \\
\hline Ciclo $6^{(1,2,3)}$ & $\langle 23,24,15,18,14,13,23\rangle$ \\
\hline Ciclo $7^{(1,2,3)}$ & $\langle 61,68,37,61\rangle$ \\
\hline Ciclo $8^{(1,2,3)}$ & $\langle 40,68,39,40\rangle$ \\
\hline Ciclo $9^{(1,2,3)}$ & $\langle 27,35,44,27\rangle$ \\
\hline Ciclo $10^{(1,2,3)}$ & $\langle 38,68,39,38\rangle$ \\
\hline Ciclo $11^{(1,2,3)}$ & $\langle 29,31,72,30,64,29\rangle$ \\
\hline Ciclo $12^{(1,2,3)}$ & $\langle 57,84,55,57\rangle$ \\
\hline Ciclo $* 13^{(1,2,3)}$ & $\langle 57,81,56,57\rangle$ \\
\hline Ciclo $14^{(1,2,3)}$ & $\langle 8,9,77,79,87,8\rangle$ \\
\hline Ciclo $15^{(1,2,3)}$ & $\langle 59,67,68,61,19,66,69,9,8,59\rangle$ \\
\hline Ciclo $16^{(1,2,3)}$ & $\langle 1,3,71,1\rangle$ \\
\hline Ciclo $17^{(1,2,3)}$ & $\langle 4,5,6,3,71,8,9,2,4\rangle$ \\
\hline Ciclo $18^{(1,2,3)}$ & $\langle 46,51,52,47,49,53,46\rangle$ \\
\hline Ciclo $19^{(1,2,3)}$ & $\langle 19,82,62,60,69,66,19\rangle$ \\
\hline Ciclo $20^{(1,2,3)}$ & $\langle 9,69,70,34,4,2,9\rangle$ \\
\hline Ciclo $21^{(1,2,3)}$ & $\langle 31,60,69,70,34,32,31\rangle$ \\
\hline Ciclo $22^{(1,2,3)}$ & $\langle 18,20,13,23,16,18\rangle$ \\
\hline Ciclo $23^{(1,2,3)}$ & $\langle 16,18,21,16\rangle$ \\
\hline Ciclo $24^{(1,2,3)}$ & $\langle 31,32,34,31\rangle$ \\
\hline Ciclo $25^{(1,2,3)}$ & $\langle 14,31,60,14\rangle$ \\
\hline Ciclo $26^{(1,2,3)}$ & $\langle 72,73,62,60,31,72\rangle$ \\
\hline Ciclo $27^{(1,2,3)}$ & $\langle 24,75,12,76,17,23,24\rangle$ \\
\hline Ciclo $28^{(1,2,3)}$ & $\langle 12,17,15,24,75,12\rangle$ \\
\hline
\end{tabular}

\begin{tabular}{|c|c|}
\hline Ciclo $29^{(1,2,3)}$ & $\langle 4,34,33,72,30,64,27,35,36,3\rangle$ \\
\hline Ciclo $30^{(1,2,3)}$ & $\langle 27,29,25,28,27\rangle$ \\
\hline Ciclo $31^{(1,2,3)}$ & $\langle 48,63,54,48\rangle$ \\
\hline Ciclo $32^{(1,2)}$ & $\langle 41,43,39,40,41\rangle$ \\
\hline Ciclo $33^{(1,2,3)}$ & $\langle 19,22,21,18,58,19\rangle$ \\
\hline Ciclo $34^{(1,2,3)}$ & $\langle 26,27,28,26\rangle$ \\
\hline Ciclo $35^{(1,2,3)}$ & $\langle 6,10,78,7,90,3,6\rangle$ \\
\hline Ciclo $36^{(1,2,3)}$ & $\langle 45,50,54,45\rangle$ \\
\hline Ciclo $37^{(1,2,3)}$ & $\langle 64,74,73,72,30,64\rangle$ \\
\hline Ciclo $38^{(1,2,3)}$ & $\langle 45,81,56,54,45\rangle$ \\
\hline Ciclo $39^{(1,2,3)}$ & $\langle 55,62,82,55\rangle$ \\
\hline Ciclo $40^{(1,2,3)}$ & $\langle 55,62,82,55\rangle$ \\
\hline Ciclo $41^{(1,2,3)}$ & $\langle 82,85,83,9,69,60,62,82\rangle$ \\
\hline Ciclo $42^{(1,2,3)}$ & $\langle 19,61,68,86,19\rangle$ \\
\hline Ciclo $43^{(1,2,3)}$ & $\langle 1,93,92,11,1\rangle$ \\
\hline Ciclo $44^{(1,2,3)}$ & $\langle 17,23,24,15,17\rangle$ \\
\hline Ciclo $45^{(1,2,3)}$ & $\langle 41,42,40,39,43,41\rangle$ \\
\hline Ciclo $46^{(1,2,3)}$ & $\langle 31,34,33,72,31\rangle$ \\
\hline Ciclo $47^{(1,2,3)}$ & $\langle 19,58,18,22,19\rangle$ \\
\hline Ciclo $48^{(1,2,3)}$ & $\langle 85,91,92,93,1,8,9,83,85\rangle$ \\
\hline Ciclo $49^{(1,2,3)}$ & $\langle 18,66,19,58,18\rangle$ \\
\hline Ciclo $50^{(1,2,3)}$ & $\langle 27,44,80,27\rangle$ \\
\hline Ciclo $51^{(1,2,3)}$ & $\langle 27,64,29,27\rangle$ \\
\hline Ciclo $52^{(1,2,3)}$ & $\langle 9,83,85,91,90,3,71,8,9\rangle$ \\
\hline Ciclo $53^{(1,2,3)}$ & $\langle 31,33,72,31\rangle$ \\
\hline Ciclo $54^{(1,2,3)}$ & $\langle 64,65,30,72,73,74,64\rangle$ \\
\hline Ciclo $55^{(1,2,3)}$ & $\langle 8,59,1,8\rangle$ \\
\hline Ciclo $56^{(1,2,3)}$ & $\langle 1,8,71,3,1\rangle$ \\
\hline
\end{tabular}

\begin{tabular}{|l|l|}
\hline \hline Ciclo $* 57^{(1,2,3)}$ & $\langle 27,89,74,64,27\rangle$ \\
\hline Ciclo $* 58^{(1,2,3)}$ & $\langle 52,88,43,39,68,86,19,82,55,57,56,54,47,52\rangle$ \\
\hline Ciclo $59^{(1,2,3)}$ & $\langle 66,69,6014,18,66\rangle$ \\
\hline
\end{tabular}


Cycles 13, 57 and 58 presented in the table above involve new corridors, and correspond to a disjunctive restriction. With the proposed methodology applied to the Colombian electrical system (using the disjunctive multi-stage transport model), 59 critical cycles were obtained, which allows the optimum solution known for this system to be found of US $\$ 500.1719851$. The execution time was $1458.51 \mathrm{sec}$ with 1417157.10 ticks. As in the previous system, the methodology proposed in this work allows to obtain better results in calculation times, that is to say, with the traditional disjunctive model the same optimal solution is obtained but with execution time of $358.17 \mathrm{sec}$ with 400551.40 ticks, which evidences the effectiveness of the proposal with cycles.

The results obtained by applying the critical cycle methodology to the multi-stage planning problem (for the Colombian system) yield exactly the same additions (corridors) as those obtained with the disjunctive linear DC model (see Tables 3, 4 and 5). It can be seen that this methodology represents an excellent option when minimizing the execution time and the computational expense in the planning problem of multi-stage transmission.
Table 5. Results stage 3.

\begin{tabular}{|l|c||}
\hline \hline Corredor & No de líneas \\
\hline$[43,88]$ & 2 \\
\hline$[15,18]$ & 1 \\
\hline$[30,65]$ & 1 \\
\hline$[30,72]$ & 1 \\
\hline$[55,84]$ & 1 \\
\hline$[27,64]$ & 1 \\
\hline$[19,82]$ & 1 \\
\hline$[68,86]$ & 1 \\
\hline
\end{tabular}

Table 3. Results stage 1.

\begin{tabular}{|l|c|}
\hline \hline Corredor & No de líneas \\
\hline$[57,81]$ & 2 \\
\hline$[55,57]$ & 1 \\
\hline$[55,62]$ & 1 \\
\hline$[45,81]$ & 1 \\
\hline$[82,85]$ & 1 \\
\hline
\end{tabular}

Table 4. Results stage 2 .

\begin{tabular}{|l|c|}
\hline \hline Corredor & No de líneas \\
\hline$[27,29]$ & 1 \\
\hline$[62,73]$ & 1 \\
\hline$[72,73]$ & 1 \\
\hline$[19,82]$ & 1 \\
\hline
\end{tabular}

\section{CONCLUSION}

This paper presents a new mathematical framework that uses a mixed integer linear programming model, improved models and a methodology to solve the planning problem. The goal is to reduce the total computational expense of transmission planning. This work shows a significant improvement from the preliminary studies made some time ago, in which the solutions were found after manual analysis in test systems. It is important to emphasize that this work not only shows an improvement in the computational effort when using these new critical cycle restrictions, but also an improvement of the traditional models that build the way to find better solutions. The computer tests show the effectiveness of the proposed methodology (critical cycles) and improved models to reduce the time to solve the planning problem, since the improved disjunctive transport model represents a novel idea to describe the planning problem without the complications of the use of Kirchhoff's second law with valuable results.

Finally, in the problem of multi-stage planning, novel results were obtained that showed the effectiveness of critical cycles. These results showed that the multi-stage DC model can be replaced by a more efficient one without including Kirchhoff's second law using the central methodology of this work. The results proved that the execution time and computation expense is significantly reduced.

\section{Conflict of Interest}

The authors confirm no conflict of interests.

\section{Acknowledgement}

This work was supported by the Planning Group in Power 
Electric Systems, GEDNOL group research and Geometry and Probability Group at the Technological University of Pereira and would like to thank the referee for his valuable suggestions that improved the presentation of this paper.

\section{References}

Correa, C., Bolaños, R., \& Escobar, A. (2014). Transmission expansion planning considering multiple generation scenarios and demand uncertainty. Ingeniare, 22 (2), 177-188.

Domínguez, A. (2014). Metodología de solución para el planeamiento de la transmisión considerando incertidumbre en la demanda y propuestas de diferentes conductores. Revista EIA-Colombia, vol. 11, 99-112.

Domínguez, A. (2018). Planeamiento multietapa a largo plazo de redes de transmisión considerando alternativas HVDC, pérdidas y contingencias. Ph.D. dissertation, Dept. Elect. Eng., Universidad Tecnológica de Pereira-Colombia.

Duque, A. (2014). Planeamiento multietapa de la expansión de redes de transmisión usando particiones de red e identificación de variables principales. M.Sc. dissertation, Dept. Elect. Eng., Universidad Tecnológica de Pereira-Colombia.

Escobar, A. (2010). Modelos usados en el planeamiento de la expansión a largo plazo de sistemas de transmisión de energía eléctrica. Universidad Tecnológica de Pereira-Colombia.

Escobar, A. (2002). Planeamiento dinámico de la expansión de sistemas de transmisión usando algoritmos combinatoriales. M.Sc. dissertation, Dept. Elect. Eng., Universidad Tecnológica de Pereira-Colombia.

Escobar, L. (2016). Long term transmission expansion planning considering generation-demand scenarios and HVDC lines. IEEE PES Transmission \& Distribution Conference and Exposition-Latin America (PES T\&D-LA).

Escobar, L. (2018). Specialized models for the long-term transmission network expansion planning problem. Ph.D. dissertation, Dept. Elect. Eng., Universidade Estadual Paulista (UNESP). SP Brasil.

Garver, L. (1970). Transmission Network Estimation Using Linear Programming. Power Apparatus and Systems, IEEE Transactions, vol. 89, 1688-1697.

Kocuk, B. (2016). A Cycle-Based Formulation and Valid Inequalities for DC Power Transmission Problems with Switching. Operations Research, vol. 64, 922-938.

Monticelli, A., Santos, A., \& Pereira, M. (1982). Interactive transmission network planning using a least-effort criterion. IEEE Transactions on Power Apparatus and System PAS, 101(10), 3919-3925.

Rahmani, M., Romero, R., \& Rider, M. (2013). Strategies to reduce the number of variables and the combinatorial search space of the multistage transmission expansion planning problem. Power Systems, IEEE Transactions, 28(3), 21642173.

Rider, M., Garcia, A., \& Romero, R. (2008). Transmission system expansion planning by a branch and bound algorithm. Generation, Transmission and Distribution, IET, 2(1), 90-99.

Romero, R., Rocha, C., Mantovaniv, J., \& Sanchez, I. (2005). Constructive heuristic algorithm for the dc model in network transmission expansion planning. Generation, Transmission and Distribution, IEE Proceedings, Vol. 152, 277-282.

Zeinaddini-Maymand, M., Rashidinejad, M., Mohammadian, M., Mahmoudabadi, M., Khorasani, H., \& Rahmani, M. (2011). An application of a modified constructive heuristic algorithm to transmission expansion planning. PowerTech, IEEE Trondheim, 1-5. 